\title{
Publishing more than reviewing? Some ethical musings on the sustainability of the peer
}

\author{
review process
}

\begin{abstract}
Based on our editorial experience, and acknowledging the regular editor grievances about reviewer disengagement at professional meeting and conferences, in this essay, we argue that the review system is in need of significant repair because hyper competition and individual incentives (like reduced teaching loads or publication bonuses) are eroding the willingness of individuals to engage in the collective enterprise of peer-reviewing each others' work on a quid pro quo basis. In response to this, we ask (i) why is it unethical for potential reviewers to disengage from the peer-review process? and (ii) what are the implications for our profession if colleagues publish more than they review? Designed as a political intervention in response to reviewer disengagement, we aim to 'politicize' the review process and its consequences for the sustainability of the scholarly community. We hope that this essay can help change attitude and behaviour for more reviewer engagement in organisational theory. Failing that, we also offer a call to action for more unorthodox approaches to reverse the development of reviewer disengagement.
\end{abstract}

Keywords: Community, Ethics, Individualism, Politics, Reviewing 


\section{Introduction}

Dear $X X X X^{1}$

Sorry I am buried right now. My projects are coming due over the next few weeks and I am almost constantly reading and commenting on them now.

Dear $X X X X$

Sorry, I have already done too many reviews this year.

We received these emails from senior scholars on sending a 'personalized' journal review invitation to her/him. In the first case, this was following the email sender's request for feedback - generously provided - on a potential journal submission, and in the second case, following the sender's accepted publication in a journal. We venture a guess that many colleagues with editorial experience in organization theory or management studies regularly receive emails of this kind - emails indicative of prioritizing one's own research agenda rather than contributing to and sustaining the community through the provision of peer review (see e.g., Treviño, 2008; Gallagher, 2013).

In the essay, we propose the thesis that the review system is in need of significant repair - not only because of frailties concerning human judgement or the exploitation of academics (Jordan, 2020; see also Macdonald and Kam, 2011), but because hyper competition (Edwards and Roy, 2016) and individual incentives (e.g., reduced teaching loads or publication bonuses or reduced teaching loads when hitting ' $A$ ' publications, see Aguinis et al., 2020) are eroding the willingness of individuals to engage in the collective enterprise of peer-reviewing each others' work on a quid pro quo basis (Jordan, 2020). By sharp contrast, those who entertain the 'give-and-take-attitude' and generously provide feedback to authors have their writing time reduced. That is, to the extent that they display prosocial and collegial behaviour (see e.g., Brewis, 2018) and agree to review for colleagues, to that extent their writing time is reduced and, consequently, they face the prospect of lagging behind in

\footnotetext{
${ }^{1}$ The names have been omitted here for the sake of blind review.
} 
terms of research outputs that carry currency in modern academia (Willmott, 2011; Butler and Spoelstra, 2012).

This development prompts us to ask two closely related questions that we believe imply significant ethical connotations. First, why is it unethical for potential reviewers to disengage from the peer-review process? Second, and relatedly, what are the implications for our profession if colleagues publish more than they review? We consider this essay as a political intervention (Gabriel, 2016) to the mis-developments that are afoot in terms of reviewer disengagement. Specifically, we paraphrase Chelli and Cunliffe's (2020) notion of "politicization of knowledge and its consequences for conducting research" to the 'politicization of the review process' and its consequences for the sustainability of the scholarly community. Given the ethical valence encapsulated in the two questions that guide our essay, this step is, we believe, long overdue and in need for a perhaps provocative reckoning with the status quo. It is long overdue because, with few exceptions (Treviño, 2008), a great deal of research articles in management studies (DeSimone et al., 2020; Ragins, 2017) and ethics journals (Borkowski and Welsh, 1998) continues to focus on the 'how to review' submissions. Combined with that fact that in some disciplines, 20 per cent of the researchers perform 69 to 94 per cent of the reviews (Kovanis et al., 2016), the former point justifies a provocative reckoning with the status quo now to highlight the political dimensions of reviewer disengagements, or the implications of reviewers refusing to participate in the process. While we recognise that there are personal and professional circumstances that can entail that not every review invitation is positively responded to, our essay is aimed at those reviewers who decline and "provide no reason at all", those that "simply don't respond" and, worse still, those who "don't review, period", even though some of them "are among the most well-known and distinguished in the Academy" (Treviño, 2008: 8). 
In what follows, we develop two ethical critiques in more detail as part of the concern about increased reviewer disengagement. First, from an ethical perspective, the uneven distribution of reviewer workloads - that is, when a small number of reviewers review the major bulk of submissions - suggests a violation of principles concerning social justice. This has been defined as "a state of affairs . . in which (a) benefits and burdens in society are dispersed in accordance with some allocation principle ...; (b) procedures, norms, and rules that govern political and other forms of decision making preserve the basic rights, liberties, and entitlements of individuals and groups; and (c) human beings . . . are treated with dignity and respect not only by authorities but also by other . . . fellow citizens" (Jost and Kay, 2010: 1122). A social justice perspective is entirely opportune in our essay as it represents an antidote, inter alia, to arbitrary or unnecessary suffering (Jost and Kay, 2010). Suffering here is implied to concern both those authors whose work struggles to be reviewed, and those few reviewers who agree to review the major volume of submissions. For the latter, it enhances the possibility of disparities in terms of career progressions, such that some colleagues (cf. first introductory quote) can rapidly progress their careers on the back of a "never-give-onlytake-attitude'.

The second point we wish to highlight here is that a limited pool of reviewers (i.e., the small volume of reviewers who do most of the reviewing most of the time) implies, by necessity, that the full possible range of expertise that theoretically exists is practically not available (Jordan, 2020). This point alerts us to the possibility that said limited expertise is less capable to detect a range of 'bugs' of a theoretical, empirical, methodological, or analytical kind in the submissions that are being reviewed ${ }^{2}$. If these bugs remain undetected and yield unreliable research, than the prospect of practise at work being informed by such

\footnotetext{
${ }^{2}$ Of note, we are not suggesting that there is an ethical imperative on journals to ensure the best reviewers are used to assess submissions. That may be theoretically laudable but practically often not feasible. Instead, we propose to think of the reviewer community like the polis in ancient Athens, which is characterised by two underlying principles of any society, namely, mutual needs and differences in aptitude as per Plato' The Republic.
} 
research raises the risk of harm for individuals and organizations (Lindebaum, 2013).

Likewise, a limited pool of reviewers can entail (too) much influence in their part in deciding what is 'good and relevant research'. That is, when a small number of reviewers possesses disproportionate influence on what gets published vis-à-vis the total number of theoretically available reviewers.

Below we turn now to elaborating in more details on the two questions that guide our essay. This is followed by casting a look into the future with a view to propose ways to counter the growing problem of reviewer disengagement.

\section{Why is it unethical for potential reviewers to disengage from the peer-review process?}

With reference to the possible suffering that can occur when social justice principles are violated, who is it that actually suffers as a result of reviewer disengagement? We count our colleagues, the authors, among them, the various communities of researchers than benefit from the publication of new studies to inform their own work, and of course, individuals and organizations whose problems can be resolved through research ${ }^{3}$. Given that the COVID 19 pandemic only accelerates and enhances the pressures on academics who have to manage increased workload as well as their responsibility as reviewers, it is easy to offer the excuse 'I'm too busy to review'. We reiterate that reviewers can have legitimate reasons both personally and professionally to sometimes (but not persistently) decline invitations. However, as everyone is busy, is it appropriate to simply focus on ourselves all the time to

\footnotetext{
${ }^{3}$ Trevino (2008) includes academic journals too, but we are not inclined to consider them in this essay, because their business model thrives on exploitation of academics. In fact, we object to the business model of large academic publishers, some of which enjoy an operating profit margin of $36 \%$ and more (Economist, 2011). Recall that the provision of academic labor - with our salaries being paid by universities - yields a product (i.e., the published article) that, in order to be accessed, requires universities and other institutions to pay a subscription fee. This is double travesty in perfection; universities pay our salary for the work we perform (including peer review), and academic publishers then charge universities to access their journals. We cannot think of another business branch where one party pays for the production of a product or service and then has to pay again to enjoy said product or service. Despite the distinctly unethical connotation of such practise, we need to relegate a deeper engagement with this issue to a future project - it is outside the scope of this essay. We are heartened, however, that the journals M@n@gement and Ephemera are open access journals not owned by large publishers.
} 
safeguard our time against the incursion of review invitations? In this regard, Trevino (2008) notes that if we "widen the lens to take consequences to others into account", then the "decision to review is quite straightforward" (p. 9). She continues argue - and we fully concur - that "if we want others to provide quality reviews of our work, we should be willing to do the same for them" (p. 9). Taking into account the presence of others who are affected by and through our (in)actions raises also the moral dimension of the review process.

Morality inherently implies a concern for others (Solomon, 1993) , which contrast with the idea of moral disengagement, defined as the "process of cognitive restructuring that allows individuals to disassociate with their internal moral standards and behave unethically without feeling distress (Newman et al., 2020: 535). We see the notion of reviewer disengagement in this light too due to the suffering it inflicts on authors and reviewers.

In relation to the second ethical point that a limited pool of reviewer expertise can diminish the quality of research and hence potentially can cause harm at work, we agree that technical clarifications on how to review certain kinds of submissions can be valuable (see e.g., DeSimone et al., 2020). However, the fact remains that not detecting those 'bugs' of a theoretical, empirical, methodological, or analytical kind in the first place poses a fundamental challenge to our purpose to advance and accumulate knowledge with a view to address important human needs (Suddaby, 2014; Tsui, 2016). But not only that; if we take a step back and entertain for a moment the question what happens if these 'bugs' are not detected in the peer review process (due to lack of broader expertise), then we are confronted with the ethical fallout of limited expertise having been brought to bear onto the review process. That is, when, for instance, empirical studies are treated as 'valid' when in fact

\footnotetext{
${ }^{4}$ Durkheim once eloquently summarised this point as follows: "It is impossible for men to live together and be in regular contact with one another without their acquiring some feeling for the totality which they constitute through having united together, without their becoming attached to it, concerning themselves with its interests and taking it into account in their behavior. And this attachment to something that transcends the individual, this subordination of the particular to the general interest, is the very wellspring of all moral activity" (1893/2014: 18).
} 
serious doubts about their validity is justified. A relevant example is a recent extended postpublication commentary (Prochilo et al., 2019) on a range of so-called 'seminal' studies on organizational neuroscience (Waldman et al., 2011; Waldman et al., 2017). Prochilo and colleagues (2019) demonstrated in these studies a lack of transparency for findings to be clearly understood, evaluated, or replicated - and the misuse of inferential tests that lead to misleading conclusions. Against the backdrop of mounting concern amongst neuroscientists themselves about the validity of neuroscientific data (Thibault and Raz, 2017; Button et al., 2013), Button and colleagues (2013) caution about the "ethical dimensions" of "unreliable research [which] is inefficient and wasteful" (p. 365). The potential damage that can be done on the back of unreliable research is well-documented (Lindebaum et al., 2018). Lastly, we cannot help but think about the sustained wave of article retractions in leading management and leadership journals in the previous decade, where post-publication scrutiny ascertained errors in the statistical analysis which then undermined the conclusions drawn from these projects (Atwater et al., 2014; Spoelstra et al., 2016).

\section{What are implications for our profession if colleagues publish more than they review?}

The struggles that we and many other editors (Driggers, 2015; Treviño, 2008) experience in enlisting the support of reviewers signifies, for us, a shift from concerns of others to more self-interested attitudes and behaviours that threaten to undermine the function of the peerreview process. It is here that the ethical becomes very functional or practical. We consider the function of peer-review to be that broadly of quality control check - as already indicated before - where peer review ensures that scientific conventions in the production of reliable and trustworthy knowledge are complied with. But fulfilling that function comes under pressure when too many academics disengage from the review process. That is, since functions "refer to the history of a behaviour, trait, or system, as well as its regular consequences that benefit the organism, or ... the system in which the trait, behaviour, or 
system is contained" (Keltner \& Gross, 1999, pp. 469, italics added), self-interested behaviour is antithetical to the idea of regular consequences that benefit our scholarly community when we support our colleagues and communities through peer review. Taking into account our own experiences, and the many published commentaries that sometimes feel like a cry for help from editors so that reviewers please engage more, we wonder about the cracks in the system - both their depths and width. We are reminded of Merton (1968), who once observed that "when the net balance of the aggregated of consequences of an existing social structure is clearly dysfunctional, there develops a strong and insistent pressure for change. It is possible . . that beyond a given point, this pressure will inevitable result in more or less predetermined directions for social change" (p. 94, italics in original). If we consider previous editorials (Treviño, 2008) and recent studies on reviewer (dis)engagement (Kovanis et al., 2016) as (at least) emerging proof that review system is becoming problematic (because too few reviewers undertake too much of the review volume), then the need for change may be right here and right now.

\section{Looking ahead and call for action}

In our essay, we expressly delineated our arguments in terms of who they seek to address not the reviewers who regularly review, not the ones who on occasion have to decline because of rival commitment (both private and professional), but those scholars, especially senior ones, who fail to have reasonable justifications for declining review invitations, those who do not respond at all to review invitations, or those who simply do not review at all to ensure their immediate self-interest of publishing is not jeopardised (see first opening quote).

By asking two closely entwined questions around the ethics of reviewer disengagement and the practical implications that follow from this for our task to advance science with a view to address human needs (in the context of organizational theory and beyond), we aimed to shine a light on the politicization of the review process and its consequences for the 
sustainability of the scholarly community. Said politicization of the review process is called for in response to reviewer disengagement because of two reasons. First, there is the violation of principles around social justice, which can entail arbitrary or unnecessary suffering (Jost and Kay, 2010). As outlined, suffering here concerns both those authors whose work struggles to be reviewed, and those few reviewers who agree to review the major volume of submissions (and thereby have less time at hand to advance their own writing). Second, we undermine our own legitimacy as social scientists and as a profession when a shrinking reviewer pool is less likely to detect cases of unreliable research. In this day and age, when populist politicians and conspiracy theorists only too eagerly proliferate their 'alternative news and facts', any report about 'unreliable' research only seems to provide ammunition to them for decrying science and at the same time imposing their preferred version of reality. In addition, there is always a risk that a small reviewer pool bears excessive influence on what gets published.

So what can be done? Should journals remunerate reviewers for their work? We respond in the negative here, because classic psychological research confirms that extrinsic motivation (i.e., contingent rewards, like financial incentives for review) often reduce and replace intrinsic motivation, where one desires to perform because of personal motives and interests (Deci et al., 1999). This well-established finding in psychological studies - where extrinsic incentives 'crowd out' intrinsic motivation - has been observed in a variety of fields, such as the provision of public goods and volunteering (Frey and Jegen, 2001) and academia itself (Gabriel, 2019). A controversial result is that individuals can feel alienated from their work when they perceive it is controlled by external incentives (Frey and Jegen, 2001). Instead, here are some, perhaps more unorthodox, musings about how to help improve the situation.

First, especially senior scholars need to stop setting the wrong example in relation to what Harley (2019) refers to as the 'heroic' publishing machine. If we follow Harley's (2019) 
observation about the countless times he has seen senior scholars boasting about their publication track record at conferences and keynote speeches, and whenever these displays are internalised as exemplary and inspiring behaviour by junior colleagues and graduate students, then the community may already have lost valuable colleague for the cause of selfinterested pursuits of publications rather than the collective effort to help develop the scholarship of colleagues through peer review. That, to reconnect with the previous discussion on functions of the review system, may already contribute to the functional consequences being superseded with dysfunctional ones over time. Therefore, to reverse this development, senior scholars should start setting the right example in their engagements with student and junior colleagues within their institutions and at professional meetings and conferences. That is, to promote more prominently the idea that participating in the review process is a way to acquaint oneself with future research, to learn about the publishing process by interacting with authors, editors and other reviewers, and to influence the spectrum of what is to be considered good and relevant research.

Second, while we hope that the arguments presented here provide some food for thought, some introspective ammunition if you will, for behavioural changes to occur, in the absence of changes in the foreseeable future, there may be a need to be shift gears and consider new ways of 'reviewer persuasion'. For instance, rather than merely whispering discontent informally at professional meetings and conferences about reviewer disengagement in future, how about journals stop accepting submissions from colleagues who have declined three and more review invitations in the span of one year, or that two reviews create a score for one submission per year for a given journal. Of course, we believe that it may not be advisable to consider this proposal as a universal law. It is self-evident that judgement and discretion need to be applied in individual cases when reviewers draw the journals' attention to their personal circumstances. But we venture a guess that purely selfinterested behaviour is likely to decline over time when we understand better that our own 
fates are intimately intwined with those of others. And if all else fails, then disincentives, in the form suggested above, may become a last resort to counter reviewer disengagement.

In sum, we argue that the combination of senior scholars setting the right kind of example, and journals introducing a mechanism that ensures a healthy review/submission ratio can induce attitudinal and behavioural changes toward greater reviewer engagement. No community can be built and sustained on the back of the type of individualism that shines through in the introductory quotes, or indeed by shifting the entire load to a small number of individuals. So next time the invitation arrives to a review a paper, we should 'think twice'(Driggers, 2015) before we decline it. There is, we should never forget, a person behind the manuscript ID who invested enormous amounts of time and energy in writing this article, a colleague that may have just submitted her/his first paper, a person whose career and livelihood depends on getting a paper accepted sooner rather than later ${ }^{5}$, or a person who has already reviewed six manuscripts this year in support of other colleagues' scholarship. Think also about the risk that a flawed piece of research may slip into publication without our broader expertise have been applied to it, and that that flawed piece of research actually does harm in the context of organizational practise. None of that is desirable if we care about our profession and our colleagues. What will you do differently in future?

\section{References}

Aguinis H, Cummings C, Ramani RS, et al. (2020) "An A Is An A": The New Bottom Line For Valuing Academic Research. Academy of Management Perspectives 34(1): 135154.

Atwater LE, Mumford MD, Schriesheim CA, et al. (2014) Retraction of leadership articles: Causes and prevention. The Leadership Quarterly 25(6): 1174-1180.

Borkowski SC and Welsh MJ (1998) Ethics and the Accounting Publishing Process: Author, Reviewer, and Editor Issues. Journal of Business Ethics 17(16): 1785-1803.

Brewis J (2018) On interference, collegiality and co-authorship: Peer review of journal articles in management and organization studies. Organization 25(1): 21-41. Butler N and Spoelstra S (2012) Your Excellency. Organization 19(6): 891-903.

\footnotetext{
${ }^{5}$ Of course, that in itself is a poor reason to provide a favourable review, but it is worth keeping that in mind in terms of tone of the review and how developmental a roadmap for the improvement of the submission that review is.
} 
Button KS, Ioannidis JPA, Mokrysz C, et al. (2013) Power failure: why small sample size undermines the reliability of neuroscience. Nat Rev Neurosci 14(5): 365-376.

Chelli M and Cunliffe AL (2020) Anticipating and Addressing the Politicization of Research. Organizational Research Methods.

Deci EL, Koestner R and Ryan RM (1999) A meta-analytic review of experiments examining the effects of extrinsic rewards on intrinsic motivation. Psychological Bulletin 125(6): 627-668.

DeSimone JA, Brannick MT, O’Boyle EH, et al. (2020) Recommendations for Reviewing Meta-Analyses in Organizational Research. Organizational Research Methods. DOI: $10.1177 / 1094428120967089$.

Driggers R (2015) Think Twice Before Declining a Manuscript Review Request: editorial. Applied Optics 54(16): ED6-ED6.

Durkheim E (1893/2014) The Division of Labor in Society. New York: Free Press.

Economist T (2011) Of goats and headaches: One of the best mediabusinesses is also one of the most resented. Retrieved from https://www.economist.com/business/2011/05/26/of-goats-and-headaches on 5 Jan 2021.

Edwards MA and Roy S (2016) Academic Research in the 21st Century: Maintaining Scientific Integrity in a Climate of Perverse Incentives and Hypercompetition. Environmental Engineering Science 34(1): 51-61.

Frey BS and Jegen R (2001) Motivation Crowding Theory. Journal of Economic Surveys 15(5): 589-611.

Gabriel Y (2016) The Essay as an Endangered Species: Should We Care? Journal of Management Studies 53(2): 244-249.

Gabriel Y (2019) The changing character of the management $\mathrm{PhD}$ and some reflections on how to arrest its descent to hollow virtuosity in producing meaningless texts. M@n@gement22(4):703-710.

Gallagher A (2013) The ethics of reviewing. Nursing Ethics 20(7): 735-736.

Harley B (2019) Confronting the Crisis of Confidence in Management Studies: Why Senior Scholars Need to Stop Setting a Bad Example. Academy of Management Learning \& Education 18(2): 286-297.

Jordan PJ (2020) Quality standards and training are important in the peer review process, but what about engagement? Industrial and Organizational Psychology 13(1): 61-63.

Jost JT and Kay AC (2010) Social justice: History, theory, and research. Handbook of social psychology, Vol. 2, 5th ed. Hoboken, NJ, US: John Wiley \& Sons, Inc., pp.11221165.

Kovanis M, Porcher R, Ravaud P, et al. (2016) The Global Burden of Journal Peer Review in the Biomedical Literature: Strong Imbalance in the Collective Enterprise. PLOS ONE 11(11): e0166387.

Lindebaum D (2013) Pathologizing The Healthy But Ineffective: Some Ethical Reflections On Using Neuroscience In Leadership Research. Jounal of Management Inquiry 22(3): 295 - 305.

Lindebaum D, Al-Amoudi I and Brown VL (2018) Does Leadership Development Need to Care About Neuro-Ethics? Academy of Management Learning \& Education 17(1): 96-109.

Macdonald S and Kam J (2011) The skewed few: people and papers of quality in management studies. Organization 18(4): 467-475.

Merton RK (1968) Social theory and social structure (Enlarged Edition). New York: Free Press.

Newman A, Le H, North-Samardzic A, et al. (2020) Moral Disengagement at Work: A Review and Research Agenda. Journal of Business Ethics 167(3): 535-570. 
Prochilo GA, Louis WR, Bode S, et al. (2019) An Extended Commentary on Post-publication Peer Review in Organizational Neuroscience. Meta-Psychology 3: 1-26.

Ragins BR (2017) Editor's Comments: Raising the Bar for Developmental Reviewing. Academy of Management Review 42(4): 573-576.

Solomon R (1993) Ethics: A short Introduction. Dubuque, IA: Brown \& Benchmark.

Spoelstra S, Butler N and Delaney H (2016) Never let an academic crisis go to waste: Leadership Studies in the wake of journal retractions. Leadership 12(4): 383-397.

Suddaby R (2014) Editor's Comments: Why Theory? Academy of Management Review 39(4): 407-411.

Thibault RT and Raz A (2017) The Psychology of Neurofeedback: Clinical interventions even of Applied Placebo. American Psychologist 72(7): 679-688.

Treviño LK (2008) Editor's Comments: Why Review? Because Reviewing is a Professional Responsibility. Academy of Management Review 33(1): 8-10.

Tsui AS (2016) Reflections on the so-called value-free ideal: A call for responsible science in the business schools. Cross Cultural \& Strategic Management 23(1): 4-28.

Waldman DA, Balthazard PA and Peterson SJ (2011) Leadership and Neuroscience: Can We Revolutionize the Way that Inspirational Leaders are Identified and Developed? Academy of Management Perspectives 25(1): 60-74.

Waldman DA, Ward MK and Becker WJ (2017) Neuroscience in Organizational Behavior. Annual Review of Organizational Psychology and Organizational Behavior 4(1): 425444.

Willmott H (2011) Journal list fetishism and the perversion of scholarship: reactivity and the ABS list. Organization 18(4): 429-442. 